elbow in a man subject for the previous year or so to boils.

The course in these cases might be compared to the breaking down of adhesions in a case of peritonitis, and the onset of a fulminant type of generalized peritonitis. But this lad gave no previous history throwing light on either onset or course. He may not have remembered or not have attached any importance to events which in the light of the subsequent catastrophe were of great moment. The case illustrates also the necessity for a much earlier diagnosis than is dreamt of at present. With such a valve, what vaccine could possibly have been of any service? In the future, the early examination of the blood by cultural methods may help in similar cases.

The use and the dosage of vaccines in these cases of septicaemia furnish another problem. One would think that the microbe circulating through all the tissues would stimulate them to respond more than a vaccine in one small spot. Again, the difference in dose between a few hundred million used in a case of acne or of boils and one million, the dose recommended to me by Dr. Houston of this city, after my second dose, is very remarkable.

Aneurysm of a valve is mentioned by most authorities, but the literature is not very fuil. I suppose there is not much to be said about it.

\section{A CASE OF ULCERATIVE ENDOCARDITIS.}

\section{A. HOULGRAVE, L.R.C.P.LonD.; M.R.C.S.ENG.}

I was sent for to see Miss —, aged 55, towards the end of February.

She was in bed lying on her back, her head and shoulders snpporterl by several pillows, her lower limbs drawn up, the soles of her feet resting on - the bed. Her face was of an earthy, dusky hue, the alae of the nose were working; the lips apart, and the angles of the mouth drawn back. She complained of her throat, which she said pained her on the left side at the angle of the jaw, which was worse whien she swallowed, and of a very acute pain at a worse when she swallowed, and of a very acute pain at a s. would meet the horizental at a level of the umbilicus, and of acute pain in the metacarpal joint of the left thumb. The joint was swollen, red, hot and painful; pain much worse in movement. The temperature was $103^{\circ}$, th pulse 120, and the respirations.40. The tongue was moist, with crcamy brown fur; the fauces congested and swollen, left tonsil entargerl, white matter at the orifices of several of the crypts, no enlargement of lymphatic glands. The chest ex panded well. The heart's apex by feeling and percussion was in the nipple line; systolic bruit at apex. No great enlargement of the right side, by percussion; no dullness above the third rib. A systolic murmur at second left intercostal space. First sound over aortic area not clear. No friction or thril felt. Lungs and pleura nothing abnormal found front or back. Urine acid; no albumen; no sugar, specific gravity 1030 , lithates. Over the spot indicated above in the abdomen she lithates pecially, were tonically contracted, and prevented further pecially, we

Warmth was applied to the abdomen, the thumb was bather in water and wrapped up in cotton-wool and bandaged. The throat was rinsed with warm salt and water, and swabbed with powdered boracic acid. This was done as of ten as the pain got worse. As to diet, she was ordered to have no milk curds, and nothing that would not go through a fine sieve, to be taken in small quantities, and not more than $2 \mathrm{oz}$. at a time; 1 grain of calomel was given followed by castor oil.

The symptoms gradually improved. Her blood was examined at the Pathological Laboratory of the University of Liverpool, with negative results.

In about a month she had a severe rigor, and it was followed by an attack of pleuropneumonia. She gradually got better of this and was sitting up. One day. I found her sitting up in an this and armchair, leaning of the chair, gasping plexion, was bathed in a clammy perspiration, she could scarcely speak, and one could scarcely feel her pulse. The usual remedies were applied and she came round. This attack was followed by blocking of the right saphena vein. She was kept in bed with the limb bandaged and gradually got better, and then she had another rigor. This was followed by plugging of some vein in the lower third of the left calf of the leg. Th same treatment was adopted, and she gradually came round.

Then one day she was out for a walk and sat on a seat. This was followed by chill and fever, but no local cause could be discovered.

By way of treatment, as soon as I felt pretty safe that there was not any acute intestinal inflammation, as appendicitis, etc., to deal with, she was given a mixture of 5 grains of quinine sulphate, 10 grains of salicine, and 5 minims of dilute sulphuric acid, three times a day, and occasionally 1 grain of calomel followed by castor oil, but the remedy was oxygen, given for ten to fifteen minutes erery hour, about sixty to ninety bubbles coming through the water per minute. Her temperature varied from $103.5^{\circ}$ the highest, to $96^{\circ}$ the lowest. The chart was typical of pyaemia.

I am thankful to say she is now in her usual health.

The oxygen was made in a generator the same as is used in the French Army, and supplied by Messi's. Oppenhiemer and Son, London.

\section{A CASE OF ABNORMAL PULSE RHYTHI.} BY

\section{WILLIAM JOHNSTONE, M.B., Ch.B.Glas.} TRANENT.

The following case exemplifies rather an unusual condition and is of interest on account of the fact that the patient to all intents and purposes is a healthy man. He is aged 65 years, of robust build and regular habits, but inclined to be stout; he has always enjoyed good health, but was told when presenting himself for life insurance about thirty years ago that he had an "intermittent" pulse.

A tracing of his pulse taken with Dudgeon's sphygmograph showed a pulse partaking of the nature of a pulsus trigeminus but exhibiting a further abnormality. A long pause occurred after the three systoles and another full systole then occurred, followed by another fairly Jong pause, this in turn being succeeded by the trigeminal condition again.

The most unaccountable fact was that on our continuing our observations the pulse took on an apparently regular. rhythm, as exemplified in the third tracing. The explana-

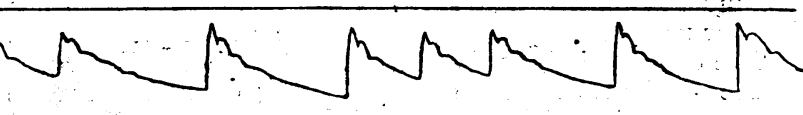

Fig. 1.

tion of these phenomena is not very clear. The only answer. which seems to me feasible is that the causs has to do with the nervous mechanism of the heart. I cannot find a similar condition recorded.

Mackenzie in his Diseases of the Heart (1908) las some tracings on page 143 which exhibit "extra" systoles after. two, three, or four beats. But these extra-systoles are not of the same volume as the regular beats themselves, as

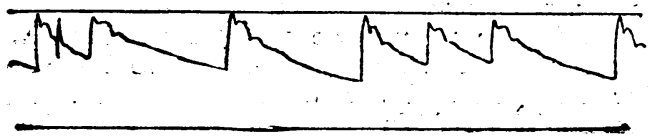

Fig. 2.

the solitary beats are in this case with a long pause before and after.

The cardiac condition of the patient was good for a man of his years, and there was no evidence of arterio-sclerosis in the vessels, as far, at least, as could be determined by examination of the accessible arteries.

On taking his blood pressure, however, we found it to register $195 \mathrm{~mm}$. $\mathrm{Hg}$ systolic and $120 \mathrm{~mm}$. Hg diastolic, with a pulse-rate of 68 .

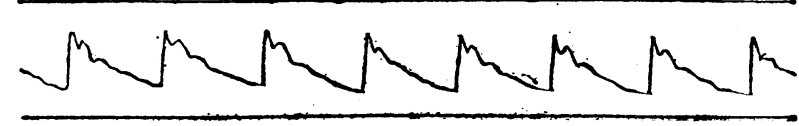

Fig. 3.

He has been put on a course of nitrites in order to determine whether the rather high blood pressure is of any etiological significance in eliciting the apparent vagary of the pulse rhythm.

The urine was examined and found normal. Dr. Thorne Thorne, in the British Medical Journal of June 12th, 
p. 1363, draws attention to the fact that a sphygmographic pulse tracing is absolutely useless as a guide to arterial blood pressure. The tracings in this case with fairly high blood pressure would not, per se, suggest the figure which was determined to be the result by the use of the Riva Rocci apparatus.

\section{EIGHTIETH ANNUAL MEETING}

OF THE

\section{程ritisly fttediral Aszariation.}

Held in Liverpool on July 19th, 20th, 22nd, 2:3rd, 2tth, $25 t h$, and $26 t h$.

PROCEEDINGS OF SECTIONS.

\section{SECTION OF SURGERY.}

Professor Rushton Parker, M.B., B.S., F.R.C.S., President.

\section{PRESIDENT'S INTRODUCTORY REMARKS.}

The business of this Section is so varied and abundant that a formal introductory address would be a needless infliction. Moreover, as it would be against the expressed wish of the Association authorities, I gladly abstain from more than a few remarks.

I must begin by expressing a hearty welcome to all who honour us by their presence and share in the proceedings.

The only topic to which I shall allude is one that must strike all by its fitness at a gathering of representative surgeons, and that is the lamented death, during-the-past half-year, of our great master, Lord Lister, the teacher of all the surgical teachers of the world; whose memory has already received such tributes as the human race can päy, in every kind of journalistic notice, at the commemoration service in Westminster Abbey, and finally at the grave in London.

'Those who came under his sway could never forget the influence produced upon themselves by his tcaching and example; searching ideas and intelligent practice united to effect the brilliant simplification of our art. Of the numerous earlier witnesses as pupils and assistants in Glasgow, in the memorable years from 1865 onward, I content- myself with mentioning two by name-sir Hector Cameron and Sir William Macewen. The contributory writings of Sir Hector Cameron are an important part of antiseptic literature, and need no further allasion. It is gratifying to know that an address will be given by Sir William Macewen in the Anatomical Section on the development and growth of boue. "Those who heard his address on the subject in the University of Liverpool in 1906 had the opportunity of learning at first hand the inportance of his original work on this topic, first communicated to the-Royal Society in 1881. The value of this work and the correction of previous ideas enabled me in 1907 to undertake and successfully accomplish the simplest, easiest, and least dangerous operation for ununited fracture, by planting in the interval small crumbs of bone clipped from adjacent callus, or, in the absence of callus, from the ends of the ununited bone. 1

An early visitor to Glasgow in 1868 was Dr. J. LucasChampionnière of Paris, one of the first and most devoted converts. and - supporters - of Lister abroad. Grateful acknowledgement is here made of his article on the life and labours of Lord Lister in the Journal de médecine et de chirurgie of February 25th, 1912.

Not having myself been a witness of Lister's own practice until 1881 in Eondon, I can still number myself with those at University College who read with avidity

1 British Medical Journal, January 11th, 19j3, p. 87 ; Proc. Roy. Soc. of Mted., June, 1908 . and discussed with profit his early papers on antiseptic surgery from 1867 onward and carried out his practice. His work on the early stages of inflammation was brought to the notice of myself and fellow students by Dr. Sharpey in 1866, but at that time I could not understand it. On preparing my own lectures on surgery in and after 1877 I found this work of essential value, with the reprints and personal advice freely sent to me by the author, who wrote in 1880 as follows:

I have sometimes been tempted to think the work I did with regard to inflammation, etc., pretty much thrown away so far as any direct influence upon my professional brethren is concerned, although I am well aware that the knowledge which I gained in that way was of the utmost value to myself, not merely as enabling me to comprehend to some extent matters in surgical pathology which had before been mysterious, but also as affording the clue to the interpretation of the apparently conflicting facts with which I found myself confronted when I began to work at antiseptic surgery. Hence it was peculiarly welcome to me to receive testimony that those early papers have proved immediately useful to one engaged, like yourself, in the teaching of surgery.

What better guides to successful practice can be found than the two remarkable cases of his in the Edinbiarg/ Medical Journal for April and August, 1858-one on spontaneous gangrene from arteritis, and the other on a case of ligature of the brachial artery, both illustrating the persistent vitality of the tissues? The knowledge obtained from the latter, many years after publication, enabled mo hopefully to deal with a case of compound dislocation of the elbow with severed main artery and vein, and to obtain complete restoration of structure and function without defect. ${ }^{2}$

Most wonderful are his latest papers in the Brirish Medical Journal for 1908 . The paper published January $18 \mathrm{th}$, p. 125, "On the preparation of catgut for surgical purposes," is a complete: description of the simplest, quickest, and most durable preparation of catgut for all purposes, with perfect tests of its efficiency added. There is a valuable editorial note on the same (p.163). On April 11th, p. 849, were published " Remárks on the treatment of fractures of the patella of long standing" (illustrated), and on June 27th, p. 1557, "Remarks on some points in the history of antiseptic surgery." This is a splendid epitome of the aims and methods of his antiseptic practice, in a space of less than two pages. With regard to the first and third of these I have ventured to say in comment:"

If these two brief papers . . . were mounted and hung up in every hospital and medical sehool for repeated stuly by all engaced in surser, they would serve an invaluable purpose by spieading and simplifying antiseptic precautions anong ail spieading and simplifying antiseptic precautions anong all encounter "minor cases," for when these "go wrong " much "major surgery" may result.

On which he wrote to me as follows:

A pril 27th, 1909.

Your letter in last Saturdar's BRITISH MEdical JocRNaL gratified me much. It will, I hope, do a great deal of good. . .

I received from him on the catgut question several more letters, which, up to August, 1909, were in his own handwriting throughout; after that others, dictated and merely signed by him, up to October, 1911, four months before the end.

A worc now about the arrangements of this Section, in the appointment of three set discussions instead of two. The Council were very desirous that the report of the special Committee on Fractures should be presented and discussed in the Section of Surgery at this annual meeting. If the officers of the Section had only known, before choosing the subjects for set discussion, the report of the Fractures Committee would have been selected as one. But the request did not ieach us until invitations had been issued and accepted for the discussions, on carcinoma

Lancet, February 16th, 1884, p. 300

3 British Medical Jocknal, April 24tb. 1909. b. 1036. 